\title{
LABOR'S SHARE OF THE SOCIAL PRODUCT
}

\author{
By Basil M. Manly, \\ Washington, D. C.
}

The threatened strike of the railroad brotherhoods came very near bringing the American people face to face with the fundamental problem of wealth distribution. In all previous strikes of national consequence the workers have come asking for a living wage or for the maintenance of an accustomed standard of living. But here were four hundred thousand men demanding not a living wage but a larger share - what they termed their fair share - of the social product. They asked, it is true, to have their share partly in increased leisure and partly in higher wages, but none the less the demand was simple and unequivocal.

To any observer in touch with the labor movement in the United States, there are unmistakable signs that in future the demands, not only of railroad employes, but of all classes of workers, will be pitched upon the same level. There will, of course, continue to be justification of demands on grounds of necessity, efficiency and ethics, but the predominant note will be a demand that labor shall have an ever increasing share of the social product, - of the newly created wealth of the nation.

This demand will come not only from industrial workers, but from working farmers, whether tenants or owners. Whether it will tend to include all forms of service performed for salaries and wages, from top to bottom, is a question that it is idle to debate, although there are indications of a strong tendency toward this extension of the conception of labor, notably the unionization of actors and federal employes. With this shift in the basis of labor's demands, it becomes of great practical as well as theoretical importance that the collection and analysis of information regarding the existing distribution of wealth and the study of past tendencies should proceed as rapidly as possible.

In the brief space of this paper I have no intention of entering into any extended discussion of the general facts regarding the present or past distribution of wealth. All that I shall attempt is to present a few figures relating directly to the steel industry, princi- 
pally as illustrative of methods of approach to the broader field. Other figures which I have collected indicate that the conclusions which may be drawn from these tables are typical of the entire field of corporate industry.

During the last few years a vast amount of data relating to costs of production has become available. In their crude form these data are almost valueless as indicating labor's share of the product. Usually they relate only to a single process, and any conclusions drawn from them are almost certain to be misleading. But where they become sufficiently complete to permit a product to be followed through completely from the extractive process until a finished form is reached, they become extremely valuable.

This method may be called for convenience that of "cumulative labor costs." It consists simply in following each product through all its stages from the extraction of the raw material to the creation of the finished product, adding each consecutive element of labor costs to those that have gone before, after making due allowance for the waste of material in each step. For example, in making woolen yarn the labor cost of raising, shearing, transporting, cleaning, carding and spinning all the wool that goes into a unit of product and into waste must be calculated and not simply the amount represented by the weight of the finished yarn.

In the accompanying table is shown the cumulative cost of all the labor that enters into the production of a ton of steel bars, known in the industry as "merchant" bars. This includes the labor of mining the ore and limestone, mining and coking the coal, transporting all three to the blast furnace, smelting the raw materials to form pig iron, converting the pig iron to steel ingots by means of the Bessemer process, rolling the ingots to form billets, and finally reheating the billets and rolling them down to form merchant bars. This is the most elaborate process in the steel ind ustry proper, but the total cost of all the labor, involving several men altogether, was only $\$ 9.40$, or 35.3 per cent of the total integrated cost of production. At the time these costs were calculated merchant bars were selling for $\$ 34.75$ a ton f. o. b. mills. Labor therefore received 27 per cent of the total value of the product. In this connection it should be remembered that the steel corporation, to which these costs apply, does not buy any raw materials, but mines coal, ore and limestone on its own properties. 


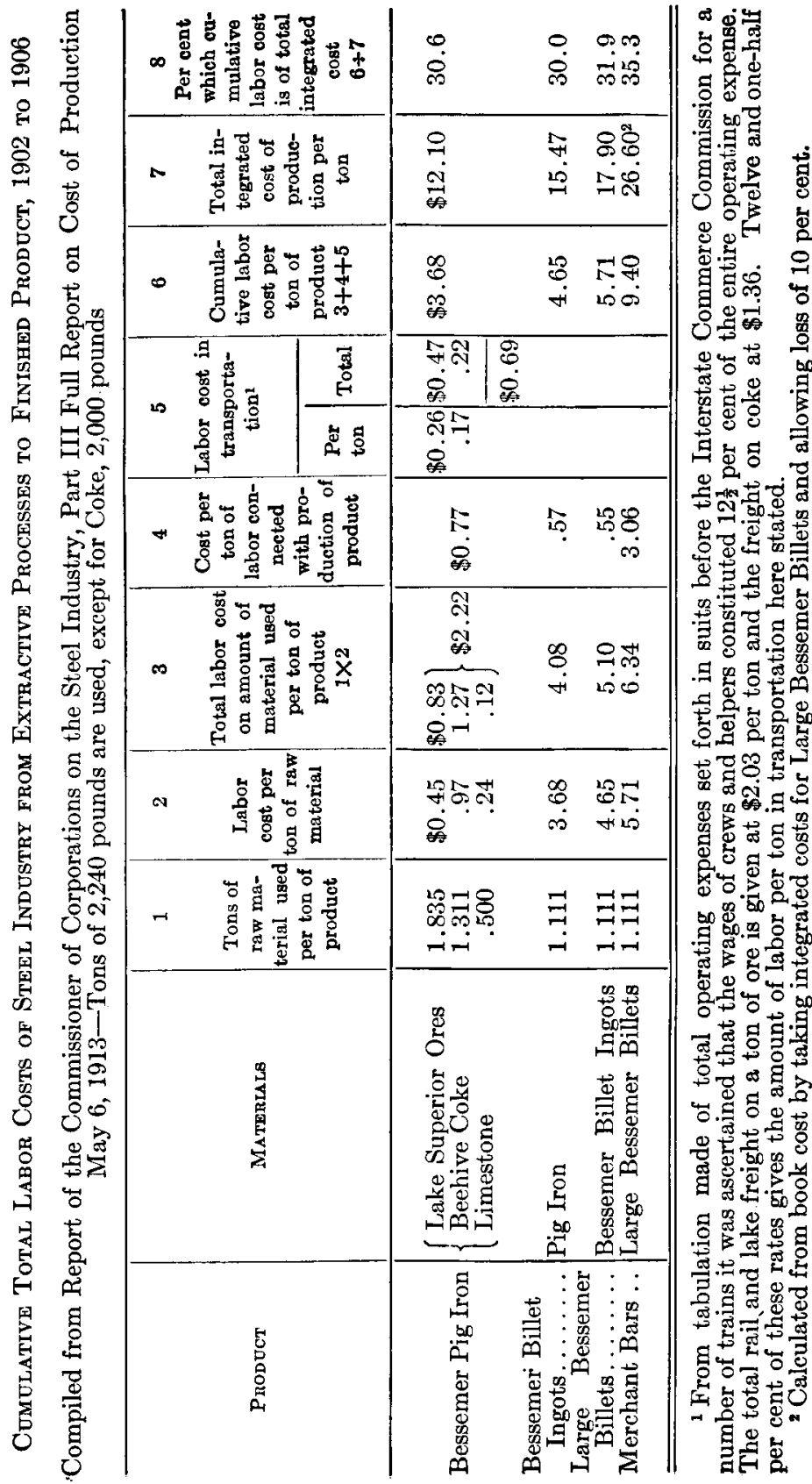


The capital employed in the steel corporation, represented by its stocks and bonds, does not get all of the difference between labor cost and selling price, for there are heavy costs for transportation, and materials for repairs and rebuilding which go to outsiders, although it may be remarked parenthetically that the same interests which control the steel corporation get the lion's share of these "outside" costs.

The group that is principally affected by the contest of labor for a larger share of the product are the common stockholders. Information regarding the actual distribution of the ownership of the common stock is therefore of the greatest interest. In the accompanying table are presented data which show not only the number of stockholders owning each number of shares of United States Steel common stock, but also the approximate amount of stock held by each group. These figures relate to 1911, but the proportions hold true today.

United States Steel Corporation

Distribution of Common Stock, 1911

\begin{tabular}{c|r|r|r|r}
\hline Number of shares & $\begin{array}{c}\text { Number of } \\
\text { shareholders }\end{array}$ & Per cont & Value of stock owned & Per cent \\
\hline & & & & \\
1 & 2,994 & 8.5 & 299,400 & \\
2 & 2,086 & 5.9 & 417,200 & \\
3 & 1,287 & 3.7 & 386,100 & 0.5 \\
4 & 604 & 1.7 & 241,600 & \\
5 & 2,440 & 6.9 & $1,220,000$ & \\
6 to 10 & 6,989 & 19.8 & $5,591,200$ & 1.1 \\
11 to 25 & 6,399 & 18.1 & $11,518,200$ & 2.3 \\
26 to 50 & 4,786 & 13.6 & $18,186,800$ & 3.6 \\
51 to 100 & 3,478 & 9.9 & $26,085,000$ & 5.2 \\
101 to 500 & 2,673 & 7.6 & $53,460,000$ & 10.4 \\
501 to 1000 & 426 & 1.2 & $31,950,000$ & 6.3 \\
1000 and over & 1,068 & 3.0 & $358,945,000$ & 70.6 \\
\hline Total & 35,230 & 100.0 & $508,302,500$ & 100.0 \\
\hline
\end{tabular}

In considering this table it must be remembered that the steel corporation is always cited as the most conspicuous example of widely distributed stock. This wide distribution as a matter of fact 
arises primarily from its policy of selling stock to its employes upon easy terms.

The essential facts to be noted are that the holders of less than twenty-five shares ( $\$ 2,500$ par value) constituting approximately 65 per cent of the total number of stockholders actually owned only 4 per cent of the stock, while the 1,068 stockholders (less than 3 per cent) with more than 1,000 shares owned 70.6 per cent of all the stock.

Essentially the same condition exists in every American corporation. During the past year I have examined nearly 300 stockholders' lists and have found that taking them all together,-big companies and little companies, banks, railroads and industrialsless than 2 per cent of the stockholders owning 1,000 shares or more hold more than half of the entire stock.

It is this concentration of ownership in the hands of a small number of exceedingly wealthy people that will sharpen labor's determination to increase its share of the product. Regardless of any theoretical conceptions of the proper distribution of wealth the struggle will be forced at least until this class, whose wealth is now very largely hereditary, has been shaken out of its position of control. 